\title{
IN MEMORIAM FREDRIK ESSCHER
}

For many Astin members Esscher's name is associated with his method for the approximation of a distribution function for which the corresponding characteristic function is known. This method was in I932 introduced for the Poisson process and in I963 extended to a general distribution function. In 1963-1964 Esscher and Bohman compared the results of this approximation for a Poisson and for a Polya process with the results of another evaluation with known precision over a wide field of the variable and of the process parameter. In a large domain of this field the agreement between the compared functions was found to be excellent. In the paper of I932 Esscher also gave the exact expression for the distribution functions defining a Poisson process in the case, where the size of a change is dependent on the parameter point at which the change has occurred. In r 965 Esscher published a paper on stop loss premiums for large portfolios under different assumptions for the risk distribution of the process. The papers mentioned above were all published in Skandinavisk Aktuarietidskrift, and the last one, in addition, summarized in the Astin Bulletin I967.

The chief field of Esscher's activity was Life Insurance. From I $92 \mathrm{I}$ to $\mathrm{I} 928$ he was actuary in Allmänna Pensionsförsäkringsbolaget and from I928 to I959 chief actuary in Skandia and affiliated companies. In his inaugural dissertation (1920) and in the 25 years Jubilee Volume of the first mentioned company (I925) he developed statistical methods for the estimation of the force of mortality, which have had a material influence of later Swedish studies of mortality. In Skandias 75 years Jubilee Volume (I930) Esscher published two theoretical papers, one on interpolation and the other on graduation with certain polynomials according to the principle of least squares. In both papers the results were applied to different functions commonly used in life insurance technique. On several occasions Esscher took a prominent part in the preparation of new technical bases for the calculation of premiums, surrender values and office values, from I928 common to all Swedish offices transacting ordinary life insurance. For his own companies 
he elaborated a system for the distribution of dividends in accordance with the principle of equity provided in the Insurance Act of 1948, which system has formed a model for many life offices. From 1950- when the life offices established the Research Council for Actuarial Science and Insurance Statistics-to I965, Esscher was chairman of the council. He was a prominent member also of other joint committees, and for a long time member of the board of the Swedish Society of Actuaries, where he later was elected as an honorary member.

Also in other fields Esscher's contributions have been highly valuable. The charge for administration costs in the premiums of Third Party Liability Insurance, since I929 compulsory for the owners of motor vehicles in traffic, has since the beginning been calculated according to ideas propounded by Esscher in I928. In r956 he published a paper for the Nordic Conference of Casualty Insurance on rating problems in Motor Insurance with particular regard to no-claim bonus. The treaty of the pool of Nordic Accident Insurance, which treaty implies individual excess cover for accidents involving more than one injured person, was in 1963 amended in main conformity with a draft given by Esscher. He also studied internal problems within Management Science, for his companies, e.g. problems connected with underwriting ans selling costs.

In an article of 1959 Harald Cramér pronounced about Fredrik Esscher that in him theoretical learning and practical ability had formed a union of rare harmony and, that he in debates used to brandish a swordblade of sharpedged steel. By the Swedish actuaries Esscher's lucid spirit and unusual ingenuity will always be commemorated.

C. Philipson 